\title{
Investigation of a $P A X 6$ gene mutation in a Malaysian family with congenital aniridia
}

\author{
P.C. Lee ${ }^{1}$, H.H. Lam ${ }^{2,3}$, S.A. Ghani ${ }^{2}$, V. Subrayan ${ }^{3}$ and K.H. Chua ${ }^{4}$ \\ ${ }^{1}$ School of Science and Technology, Universiti Malaysia Sabah, \\ Jalan UMS, Kota Kinabalu, Sabah, Malaysia \\ ${ }^{2}$ Department of Ophthalmology, Queen Elizabeth Hospital, \\ Kota Kinabalu, Sabah, Malaysia \\ ${ }^{3}$ Department of Ophthalmology, University of Malaya Medical Center, \\ Kuala Lumpur, Malaysia \\ ${ }^{4}$ Department of Biomedical Science, Faculty of Medicine, \\ University of Malaya, Kuala Lumpur, Malaysia \\ Corresponding author: K.H. Chua \\ E-mail: khchua@um.edu.my
}

Genet. Mol. Res. 13 (2): 3553-3559 (2014)

Received March 12, 2013

Accepted July 12, 2013

Published March 24, 2014

DOI http://dx.doi.org/10.4238/2014.March.24.15

\begin{abstract}
Mutations in the $P A X 6$ gene that cause aniridia have been identified in various ethnicities but not in the Malaysian population. Therefore, the objective of this study was to investigate the PAX6 mutation in a Malaysian family with congenital aniridia. In this study, a complete ophthalmic examination was performed on a Dusun ethnic family with aniridia. Genomic DNA was extracted from the peripheral blood of the subjects and screened for the PAX6 gene mutation using polymerase chain reaction amplification high-resolution melting curve analysis (PCR-HRM) followed by confirmation via direct DNA sequencing. A heterozygous $\mathrm{G}$ deletion (c.857delG) in exon 7 causing a frame shift in $P A X 6$ was identified in all affected family members. Genotype-phenotype correlation analysis revealed congenital cataract and all affected family members showed a similar spectrum of aniridia with no phenotypic variability but with differences in severity that
\end{abstract}


were age-dependent. In summary, by using a PCR-HRM approach, this study is the first to report a $P A X 6$ mutation in a Malaysian family. This mutation is the cause of the aniridia spectra observed in this family and of congenital cataract.

Key words: Aniridia; Pax6; Mutation; Malaysian; PCR-HRM; Sequencing

\section{INTRODUCTION}

Aniridia is a panocular disorder characterized by iris hypoplasia and other anterior and posterior eye defects, leading to severe visual impairment. It is caused by mutations in the PAX6 gene that encodes a transcription factor regulating processes during ocular morphogenesis and forebrain development (Georgala et al., 2011). The PAX6 gene is 26 kilobases $(\mathrm{kb})$ long, located on chromosome 11p13, and contains 14 exons. The PAX6 transcription factor recognizes its target genes via a paired domain and homeodomain at the PAX6 Nterminus (Mishra et al., 2002). Most mutations in PAX6 have been detected by single-strand conformation polymorphism methods or by direct sequencing of the PAX6 exons. To date, more than 700 mutations have been identified in PAX6, which are catalogued in the PAX6 mutation database and which are associated with a wide spectrum of aniridia in different populations (http://lsdb.hgu.mrc.ac.uk/home.php?select_db=PAX6).

In this study, we applied an approach that is relatively rapid to identify mutations in PAX6 using polymerase chain reaction (PCR) amplification high-resolution melting curve (HRM) analysis and report the first case of a PAX6 mutation identified in Malaysia.

\section{MATERIAL AND METHODS}

\section{Subjects and DNA extraction}

We investigated a Dusun ethnic family of 4 generations from Kota Belud, a remote area of Sabah, Malaysia. The Dusun tribe is indigenous to Sabah and of Austronesian ancestry. Eight of the family members were diagnosed with aniridia and were given complete ophthalmic evaluation. It is of note that the severity of the aniridia phenotype in this family was very variable, ranging from mild in a 2-month-old infant (P8) to severe in the oldest family member aged $70(\mathrm{P} 1)$. The pedigree of the family is shown in Figure 1. Two non-affected members of the family and 10 unrelated healthy controls were also recruited for this study. Peripheral blood was collected from the subjects with informed consent, and genomic DNA was extracted using a similar conventional method as reported previously (Chua et al., 2009; Tan et al., 2010). This study was approved by The Ministry of Health Medical Research Ethics Committee, Malaysia (NMRR-09-482-4024).

\section{PCR-HRM analysis and sequencing}

A wide screening for PAX6 gene mutations was carried out using a PCR-HRM approach. Briefly, primers used for amplification of the 13 exons in the PAX6 gene were as 
previously reported (Glaser et al., 1992). These primers were checked using in silico PCR to ensure that they targeted the correct loci (Thong et al., 2011; Chua et al., 2011; Ng et al., 2012a). Next, conventional thermal cycler-based PCR for optimizing PCR conditions was carried out. The optimized conditions were used in a 7500 Fast Real-Time PCR system (Applied Biosystems, USA) for PCR-HRM analysis. The reaction consisted of $20 \mathrm{ng}$ genomic DNA in a final volume of $20 \mu \mathrm{L}$, which contained $0.3 \mu \mathrm{M}$ of each primer and $10 \mu \mathrm{L} 2 \mathrm{X}$ MeltDoctor ${ }^{\mathrm{TM}}$ HRM Master Mix (Applied Biosystems). The PCR cycling program was as follows: initial denaturation at $95^{\circ} \mathrm{C}$ for $10 \mathrm{~min}$, followed by 40 cycles of denaturation at $95^{\circ} \mathrm{C}$ for $15 \mathrm{~s}$ and annealing and elongation at $60^{\circ} \mathrm{C}$ for $1 \mathrm{~min}$. Analysis of PCR melting curve dissociation was performed after the amplification in the same real-time PCR system. The melting curve program used was that of $\mathrm{Ng}$ et al. (2012b): denaturation at $95^{\circ} \mathrm{C}$ for $10 \mathrm{~s}$, annealing at $60^{\circ} \mathrm{C}$ for $1 \mathrm{~min}$, high-resolution melting at $95^{\circ} \mathrm{C}$ for $15 \mathrm{~s}$, and final annealing at $60^{\circ} \mathrm{C}$ for $15 \mathrm{~s}$. In this program, short PCR amplicons were allowed to denature and re-anneal before the high-resolution melting. The change in fluorescence signal due to the dissociation of DNA duplexes and the release of DNA-binding dye in the melting step were monitored in real time. The HRM curve profile was analyzed using the HRM analysis software for Windows ${ }^{\circledR}$ version 2.0.1 with fluorescence normalization. Finally, direct DNA sequencing was also performed using an Applied Biosystems 3130 automated sequencer to confirm any mutations identified by the PCR-HRM method.

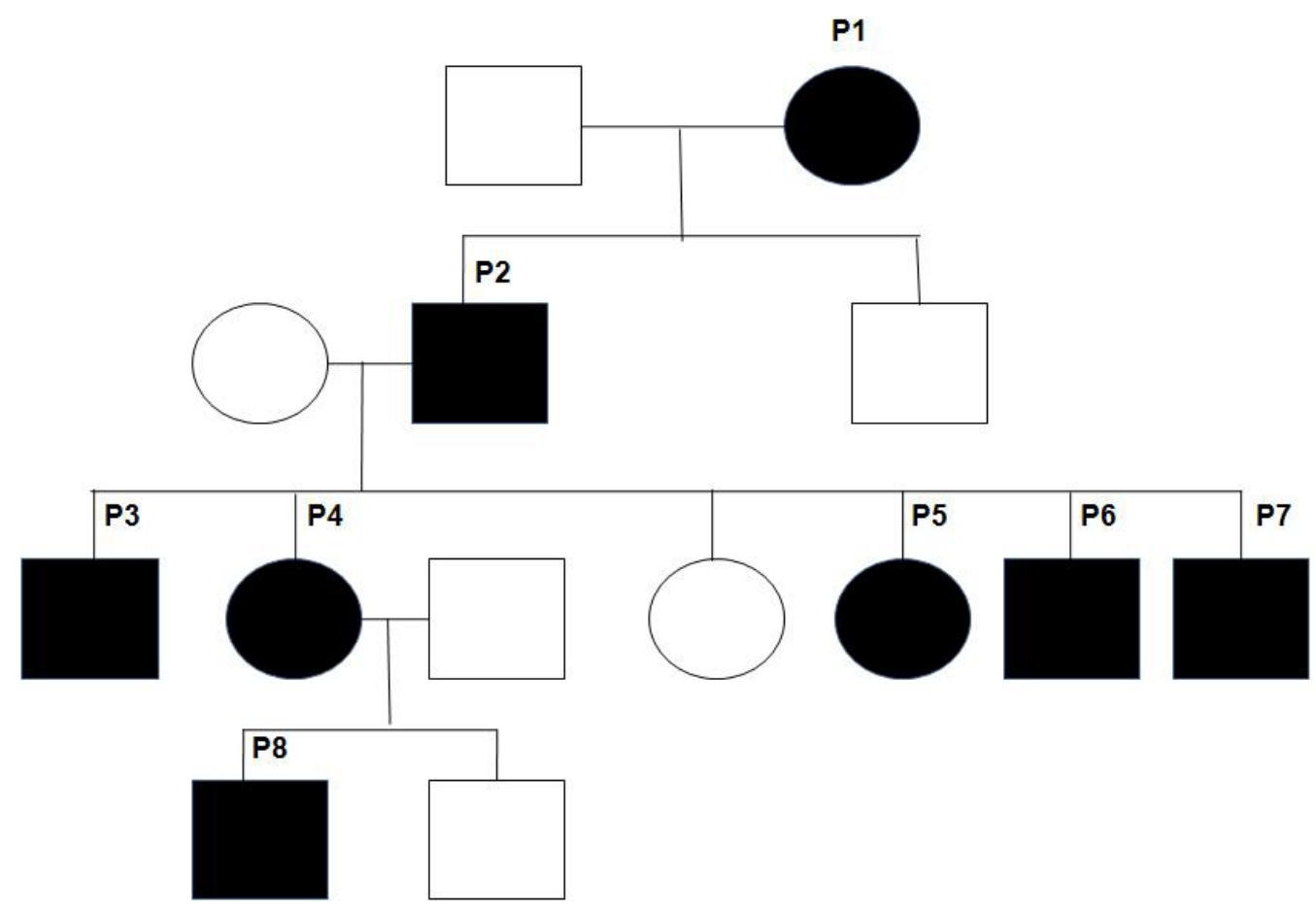

Figure 1. Pedigree of a Dusun family of four generations with aniridia. Filled symbols represent subjects with aniridia and open symbols represent normal subjects. 


\section{RESULTS}

Real-time PCR with HRM curve analysis indicated differences in the shape of the melting curve of the PCR-amplified exon 7 of the PAX6 gene in the aniridia patients but not in the controls (Figure 2). In addition, direct sequencing indicated a heterozygous $\mathrm{G}$ deletion (c.857delG) in the exon 7 of PAX6 (Figure 3). This deletion generates a frame shift and a premature termination codon in the $P A X 6$ open reading frame, resulting in a transcript that is recognized by the nonsense-mediated mRNA decay system that prevents the accumulation of truncated proteins (Byers, 2002). We identified the same (c.857delG) deletion in all affected family members, indicating that this single mutation is the cause of the aniridia spectrums observed in this family. We also analyzed the genotype-phenotype correlation arising from the c.857delG mutation in the PAX6 gene. All family members diagnosed with bilateral aniridia displayed bilateral jerky eye movement, and this symptom manifested at birth because it was already observed in P8, the 2-month-old infant. P2, the father aged 55, had a Snellen acuity of less than 6/48 and required a low-vision aid. The infant's siblings, P3-P7, only required glasses to improve their vision. We were unable to determine the visual acuity in the 2-month-old infant with the same accuracy as in the adults. All patients also developed photophobia. Further examination revealed the presence of a bilateral horizontal nystagmus. Figure 4 shows the phenotypic expression of the PAX6 gene with the identified mutation. All patients had clear microcorneas measuring only about $10 \mathrm{~mm}$. In P1 and P2, the presence of bilateral cornea opacity and vascularization demonstrated that the severity of the disorder increases with the age of the affected individuals. Nevertheless, the whole lens and zonules were visible and subluxation was not observed in any patient. P2, who had been diagnosed with bilateral cataract, had undergone eye surgery 18 years before this study and wore aphakic glasses. All other affected family members had received no treatment at the time of this study.

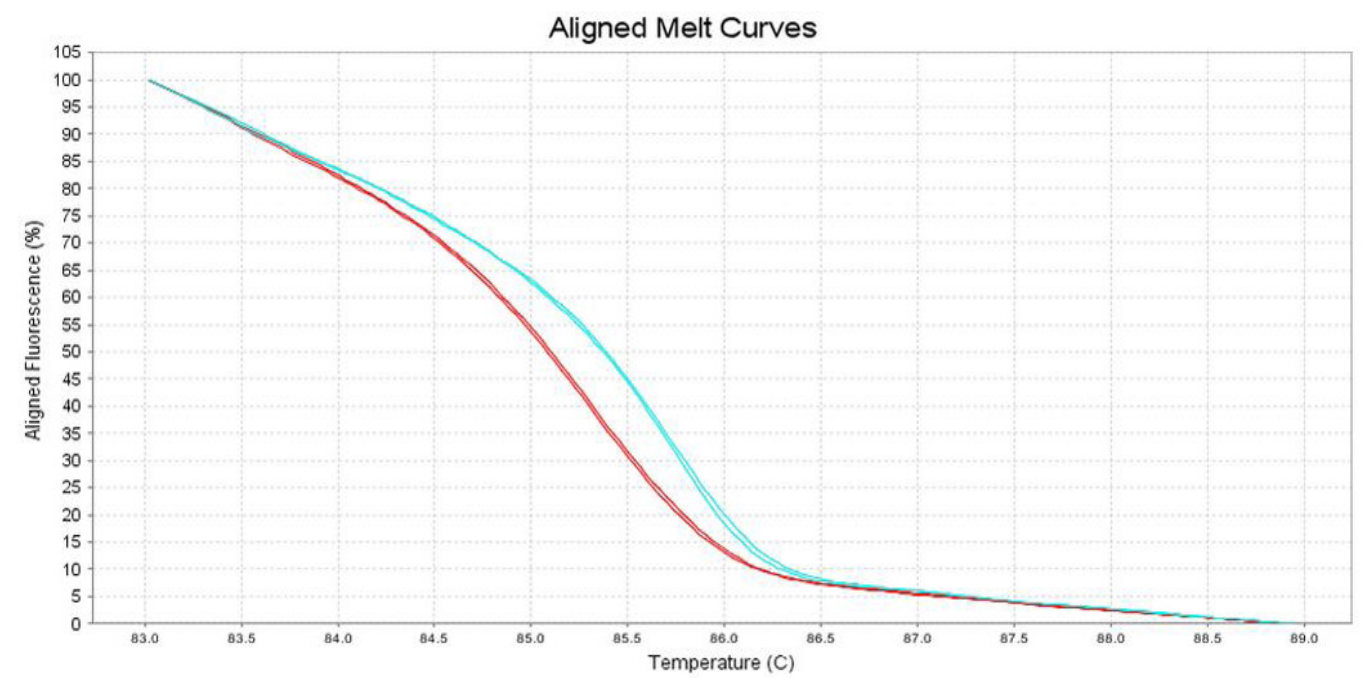

Figure 2. Melt curve analysis of the $P A X 6$ mutation in patient samples. Normal (red) and mutated (blue) sequences of the $P A X 6$ exon 7 are presented in aligned melt curves. 


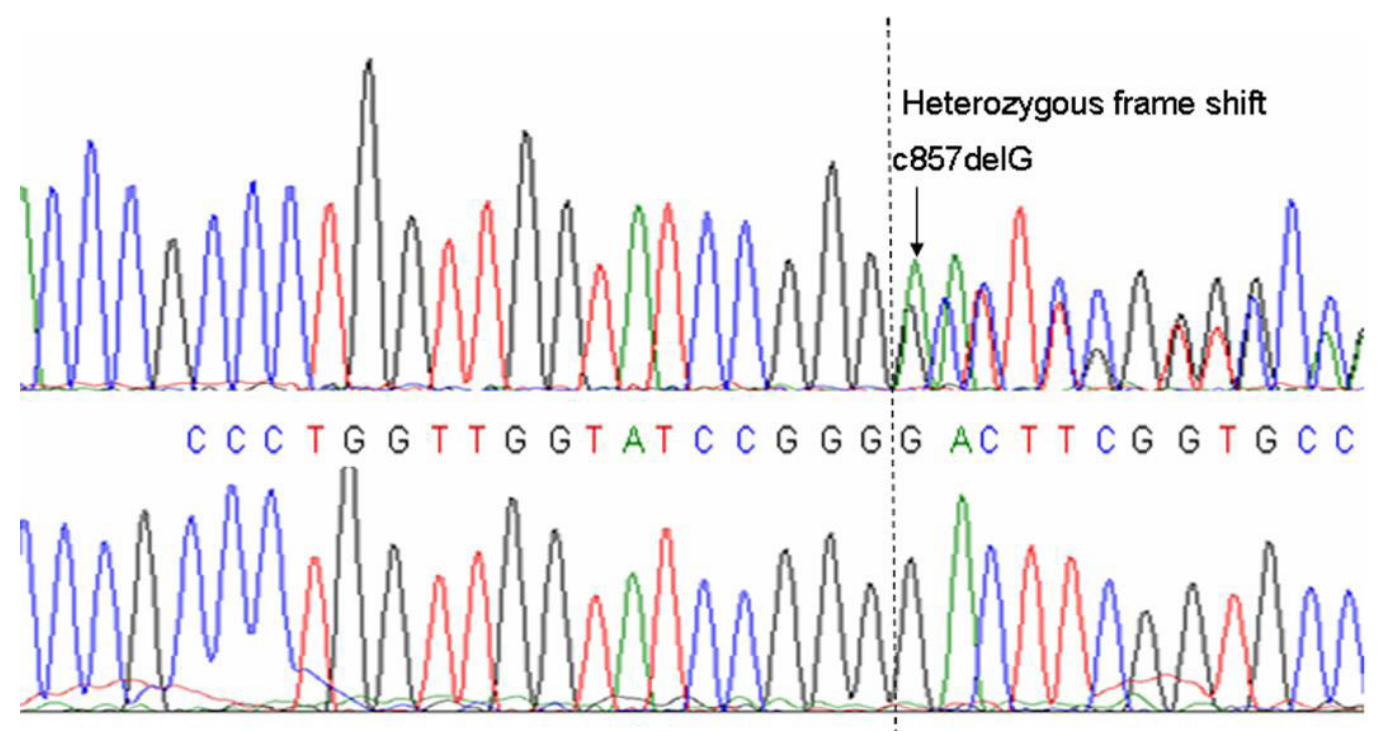

Figure 3. PAX6 gene mutation analysis by direct sequencing of the PCR products of exon 7. A heterozygous deletion of a $\mathrm{G}$ residue at nucleotide 857 generating frame-shift in one of the DNA strand compared to a normal sequence. Arrow indicates the location of the deletion.

A

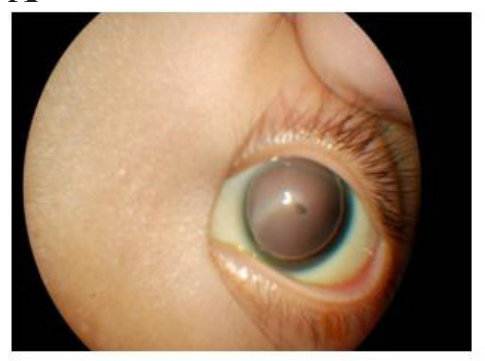

C

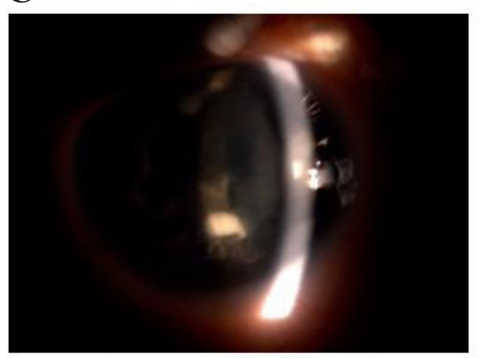

B

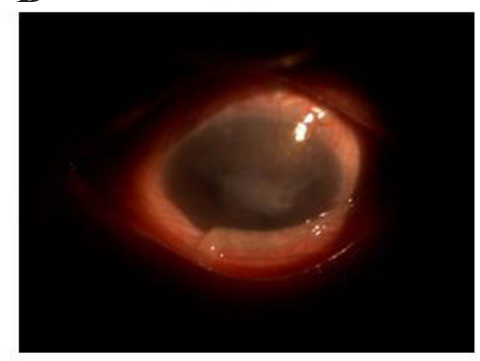

D

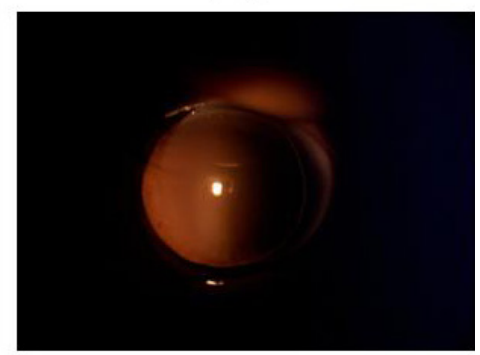

Figure 4. Examination of whole lens and zonules was visible (A) and no lens subluxation but cataractous in P6, P2, P5 and P7 (B-D) bilateral nystagmus with aniridia and cataractous lens. 


\section{DISCUSSION}

Real-time PCR with HRM curve analysis is an approach for detecting genetic variants and mutations based on the theory of PCR amplicon melting (dissociation). Differences in Tm among the PCR amplicons from exon 7 of the PAX6 gene resulted in melting curve difference that suggested the presence of an SNP heterozygote in this exon. The detection of the $P A X 6$ mutation in this case study is very useful for genetic counseling and prenatal diagnosis. This study showed that the congenital cataract phenotype observed in these individuals is associated with the frame-shift mutation identified in PAX6. In this disorder, the eye lens may develop cataracts that may have a significant impact on visual acuity by the 3rd decade of life as manifested in P1 and P2. Approximately $12 \%$ of the mutations recorded in the Human PAX6 Mutation Database do not result in cataracts. Nevertheless, a similar frame-shift mutation in a Chinese family has been reported to generate the congenital cataract phenotype (Song et al., 2005). This phenotype had also been reported to be associated with missense mutations in exons 1-6 of PAX6 at the region of its paired domain with subsequent variability in severity (Glaser et al., 1994; Gronskov et al., 1999; Cai et al., 2010). It is worth noting that all the family members affected by aniridia had satisfactory intraocular eye pressures. None of the patients developed glaucoma or foveal hypoplasia, indicating that the mutation reported here appears to inhibit the function of PAX6 less than other reported PAX6 mutations that allow normal optic nerve development. All affected members in this family harboring the c.857delG mutation exhibited a similar spectrum of aniridia with no phenotypic variability but with differences in severity. The variability in severity might be caused or influenced by other gene products belonging to diverse families of transcription factors or cotranscription factors such as PAX2, SOX, MITF, and others that might interact with PAX6 during cellular development (Kamachi et al. 2001; Planque et al., 2001).

In conclusion, to the best of our knowledge, this is the first analysis of an aniridia mutation using PCR-HRM analysis that overcomes the low rate of detection of PAX6 mutations. This is also the first study reporting a frame-shift mutation (c.857delG) in exon 7 of the PAX6 gene in a Dusun family and that describes the consequences of this mutation, which is often underrepresented in aniridia. We suggest that the c.857delG mutation plays a causative role in the phenotypes reported in this family. Although approximately $50 \%$ of aniridia cases reported include glaucoma and foveal hypoplasia, these phenotypes were not observed in the family examined in this study. The frame-shift mutation in PAX6 generated a limited spectrum of aniridia and congenital cataract developed at different ages; therefore, the aniridia disorder requires lifelong management.

\section{ACKNOWLEDGMENTS}

Research supported by the University of Malaya Research Grant (\#RG494-13HTM).

\section{REFERENCES}

Byers PH (2002). Killing the messenger: new insights into nonsense-mediated mRNA decay. J. Clin. Invest. 109: 3-6.

Cai F, Zhu J, Chen W, Ke T, et al. (2010). A novel PAX6 mutation in a large Chinese family with aniridia and congenital cataract. Mol. Vis. 16: 1141-1145.

Chua KH, Lau TP, Tee ZY, Tan SY, et al. (2009). Genetic polymorphisms of the IL-1 511 and +3954 SNPs in the 
Malaysian SLE patients. J. Health Sci. 55: 657-662.

Chua KH, Lian LH, Kee BP, Thum CM, et al. (2011). Identification of DLG5 and SLC22A5 gene polymorphisms in Malaysian patients with Crohn's disease. J. Dig. Dis. 12: 459-466.

Georgala PA, Carr CB and Price DJ (2011). The role of Pax6 in forebrain development. Dev. Neurobiol. 71: 690-709.

Glaser T, Walton DS and Maas RL (1992). Genomic structure, evolutionary conservation and aniridia mutations in the human PAX6 gene. Nat. Genet. 2: 232-239.

Glaser T, Jepeal L, Edwards JG, Young SR, et al. (1994). PAX6 gene dosage effect in a family with congenital cataracts, aniridia, anophthalmia and central nervous system defects. Nat. Genet. 7: 463-471.

Gronskov K, Rosenberg T, Sand A and Brondum-Nielsen K (1999). Mutational analysis of PAX6: 16 novel mutations including 5 missense mutations with a mild aniridia phenotype. Eur. J. Hum. Genet. 7: 274-286.

Kamachi Y, Uchikawa M, Tanouchi A, Sekido R, et al. (2001). Pax6 and SOX2 form a co-DNA-binding partner complex that regulates initiation of lens development. Genes Dev. 15: 1272-1286.

Mishra R, Gorlov IP, Chao LY, Singh S, et al. (2002). PAX6, paired domain influences sequence recognition by the homeodomain. J. Biol. Chem. 277: 49488-49494.

Ng ZX, Kuppusamy UR, Tajunisah I, Fong KC, et al. (2012a). 2245G/A polymorphism of the receptor for advanced glycation end-products (RAGE) gene is associated with diabetic retinopathy in the Malaysian population. $B r . J$. Ophthalmol. 96: 289-292.

Ng ZX, Kuppusamy UR, Tajunisah I, Fong KC, et al. (2012b). Investigation of SLC2A1 26177A/G gene polymorphism via high resolution melting curve analysis in Malaysian patients with diabetic retinopathy. J. Diabetes Complications 26: 388-392.

Planque N, Leconte L, Coquelle FM, Martin P, et al. (2001). Specific Pax-6/microphthalmia transcription factor interactions involve their DNA-binding domains and inhibit transcriptional properties of both proteins. J. Biol. Chem. 276: $29330-29337$.

Song S, Liu Y, Guo S, Zhang L, et al. (2005). A novel PAX6 gene mutation in a Chinese family with aniridia. Mol. Vis. 11: 335-337.

Tan JA, Lee PC, Wee YC, Tan KL, et al. (2010). High prevalence of alpha- and beta-thalassemia in the Kadazandusuns in East Malaysia: challenges in providing effective health care for an indigenous group. J. Biomed. Biotechnol. 2010.

Thong KL, Lai MY, Teh CS and Chua KH (2011). Simultaneous detection of methicillin-resistant Staphylococcus aureus, Acinetobacter baumannii, Escherichia coli, Klebsiella pneumoniae and Pseudomonas aeruginosa by multiplex PCR. Trop. Biomed. 28: 21-31. 